\title{
Organizational and technical aspect of quality management of food industry testing laboratories
}

\author{
Irina Zaytseva ${ }^{1, *}$ and Tatyana Setrakova ${ }^{1}$ \\ ${ }^{1}$ Don State Technical University, Gagarin sqr, 1, 344003 Rostov-on-Don, Russia
}

\begin{abstract}
The present study describes the impact of three quality management principles on the organizational capacity of food industry testing laboratories. The study also intends to create a formalized representation of the effect of organizational and technical factors on the quality of services provided. Key words: management, quality management principles, organizational capacity of the company, corporate culture, testing laboratories.
\end{abstract}

\section{Introduction}

Quality management is a coordinated operation directed at company management and administration in the aspect of quality. In the concept of systematic analysis, this definition formalizes the objective function of ISO 9000-2015 standards. The tool for addressing this function is the application of quality management principles.

Modern test laboratories are complex organizational systems. The features of these systems exclude the possibility of a unified description of all aspects of their functioning (based on common laws, methods, apparatus, etc.) and require systematic analysis and synthesis, i.e. there is no single recipe for organizational systems, there are only single management principles.

The up-to-date quality management system (QMS) includes:

- Firstly, strict structural organization of informational processes with feedback;

- Secondly, a pronounced human factor (creativity, intuition, foresight, improvisation);

- Thirdly, the skill of making creative solutions and their operational implementation.

The company's organizational capacity consists of all these essentials.

The article considers the impact of three quality management principles on the organizational capacity of testing laboratories ("systematic approach", "leader's position", "personnel's involvement"), the paper also seeks to create a formalized representation of the impact of organizational and technical factors on the quality of services provided.

\section{The impact of the principle "system approach»}

\footnotetext{
* Corresponding author: ia zaytseva@mail.ru
} 
Table 1 represents organizational capacity essentials and the influence of quality management principles on these essentials.

Organizational management systems belong to the category of complex systems that's why they should be analyzed with the help of both descriptive and technical engineering approaches.

The principle of the systematic approach is described as the development and realization of a process-oriented approach in management. The process-oriented approach had resonated widely in world society. It is the basis of a quality management system (QMS), and essentially a focused reflection of management activities through business processes.

Table 1. Essentials of organizational capacity

\begin{tabular}{|l|l|l|}
\hline Essentials of capacity & \multicolumn{1}{|c|}{ Principles } & \multicolumn{1}{c|}{ Influence on the capacity } \\
\hline $\begin{array}{l}\text { 1. The rationality of } \\
\text { structure and } \\
\text { selection of business } \\
\text { processes }\end{array}$ & $\begin{array}{l}\text { Systematic and } \\
\text { process-oriented } \\
\text { approaches }\end{array}$ & $\begin{array}{l}\text { Ensuring compliance of organization } \\
\text { structure with information } \\
\text { environment, oriented on the } \\
\text { customer; coherence business } \\
\text { processes with goals }\end{array}$ \\
\hline $\begin{array}{l}\text { 2. Corporate culture } \\
\text { of production }\end{array}$ & $\begin{array}{l}\text { Manager's leadership } \\
\text { and employee } \\
\text { involvement }\end{array}$ & $\begin{array}{l}\text { Creation of social atmosphere of } \\
\text { interests of employees }\end{array}$ \\
\hline $\begin{array}{l}\text { 3. Adaptability and } \\
\text { dynamism }\end{array}$ & $\begin{array}{l}\text { Systematic approach, } \\
\text { manager's leadership } \\
\text { and personnel's } \\
\text { involvement }\end{array}$ & $\begin{array}{l}\text { Putting in a place systematic } \\
\text { management - the process of } \\
\text { operational management in decision- } \\
\text { making. }\end{array}$ \\
\hline
\end{tabular}

Organizational structures analysis of modern companies has revealed that the operations management system of those companies is functional management, based on the administrative-command management system of the company. This is a bright example of a linear functional vertical structure of operations management without horizontal ties. A systematic functional approach applied to management, implemented in such kinds of structures, destroys the unity and coherence of separate management processes. In practice, this results in occasionally insurmountable differences between company functional departments.

This is the first reason for difficulties in establishing QMS in the context of domestic companies.

Realization of a systematic approach in QMS provides for the establishment of management of horizontal processes, i.e. organizational system's reorientation from functional control to governance set of processes and outcomes, which should improve the system's efficiency and company's competitiveness.

The concept of functional management, formulated by F. Taylor in 1911, was originally considered as a form of a systematic approach applied in management. Until the 1980s this concept had dominated the world economy and lived up to its purpose. During its existence, functional management had spent its resources for the improvement and started to lose to more progressive process management, which dominates now. The new approach has become a basis for the appearance of the latest management technologies. The standards ISO9000 with regulatory requirements for QMS include the most significant management technologies, based on a new approach $[1,4,5,13,14]$.

Though there are multiple serious deficiencies of functional management, applied in the modern domestic companies, we'd like to note the only one deficiency concerning the control system. As a rule, functional management provides for the establishment of supervisory 
bodies, that must improve the company's effectiveness on the matters of the company's activity, including quality service. As a result, this approach makes the system focused on strengthening responsibility. Strengthening responsibility method results in a situation when perpetrators come across with multiple operative instructions. The severity of punishment for mistakes and not necessary recourses pushes them to make the commitments $[2,3,7,17]$.

\section{The impact of the principles "managers' leadership and employee engagement»}

Increasing punishments don't contribute to creating conditions of improving corporate culture, which characterizes the quality workplace relationship.

A lack of conditions for improving company culture is the second reason for difficulties in establishing QMS.

The quality management principles (manager's leadership and employee involvement) play a crucial role in improving company culture.

When functional management dominates the company, the staff is generally aimed to please the chief, meanwhile, the main aim of the chiefs is to control employees. The new technological environment has transformed the "Producer market" into a "Consumer market" and demands the development of overall production culture, manager's culture, and their way to the people $[6,8,12]$.

Unfortunately, we have to note that supervision in the quality control systems is the function of the department of quality assurance in the majority of domestic companies (even with QMS). Assigning responsibility for quality assurance only to the head of DQA and senior instructors of production units don't correspond to quality management principles. It is an outdated type of quality assurance system, which bases on the rule of "detection of impairments" of the production only during the final inspection instead of prevention of low quality during each stage of production.

The modern theory of quality management bases on the following framework for corporate culture:

- The quality service can not be assured by inspection, that is by technical control procedures. The assurance of quality service needs including in the process from the first stages of its conceptual design. The famous engineer's postulate is the following: "In the stage of planning we should provide a basis for quality then we need assure quality in the stage of production and, finally, we have to maintain it in the stage of exploitation."

- The problems connected with quality services are only in $15 \%-20 \%$ cases caused by direct perpetrators of the production process. The management system is responsible for the low quality of services in $80 \%-85 \%$ of cases. Therefore, the problem-solving demands targeted adjustment and not urgent and punishing measures.

- The necessary condition for quality assurance is employee involvement with a proper degree of responsibility. The control would be much more effective if we focus on all processes and not on output [9-11].

In establishing and functioning of QMS, one of the most vital aims of company management is personnel's involvement in the system, their development, allocation of responsibility, and delegation of appropriate authority. According to the top managers, all efforts to introduce QMS come across the staff's resistance until the "people's critical mass" (about $75 \%$ of staff) accumulate, want to create QMS, and know how to do it. It is the quality management principle "leadership of the manager." QMS can only be successful if management systems understand these main provisions of the corporate culture.

Finally, the third reason for challenges in establishing QMS is difficulties of the organization's operative management system with a high level of dynamism and adaptivity in carrying out rapidly changing challenges in production. 
However, the thing that systems of organizational management is formed during operational activity is still considered. This is nothing more than a leader's delusion because improving governance should be science-based.

\section{Analysis of the impact of organizational factors on the quality of services provided}

A systematic approach based on descriptive analysis proves a high level of impact on quality.

Quality services may be represented in the function of certain quality factor $\bar{A}(C)$ acting at a certain point $t$, i.e.:

$$
K_{t}=f_{t}\left\{\bar{A}_{t}(C)\right\}
$$

The function shows, that quality which is characterized by a certain generalized indicator $K_{t}$, is independent of direct input $C$, and depends on a generalized quality factor $\bar{A}_{t}(C)$. Indeed, the quality factor $\bar{A}_{t}(C)$ is a vector-valued function, which is a notional (abstract) identification of controlled and uncontrolled factors of distinctive qualitative nature, namely, technical and economical, organizational and social character of impact on quality. These factors collectively determine public needs and material costs, which are necessary for reaching the required quality level at a certain point $[15,16]$.

The type of function should characterize the general tendency of connection; besides, the type of function depends on common patterns of interaction and intersectionality between quality service, common needs, and outputs, which are necessary for reaching set targets of these features.

According to provisions of progress standardization, ties of the quality indicator of the final test result mathematically may be represented in the following:

$$
K_{t}=K_{t \max }-\left(K_{t \max }-K_{0}\right) \exp \left[-\left\{\bar{A}_{t}(C)\right\}\right]
$$

where $K_{t \max }, K_{0}$ is a maximum value and entry level of $K_{t}$ on this structural and technological basis, respectively.

Since organizational and technological factors incoming in $\bar{A}_{t}(C)$ are particularly interesting for our study, it is useful to analyze how the quality factor is connected with components incoming in the equation (2).

The quality factor, by definition, corresponds:

$$
A_{t}(C) \Rightarrow \ln \frac{K_{t \max }-K_{0}}{K_{t \max }-K_{t}}=\widetilde{a}_{t}
$$

With simple transformation and on the condition that $K_{0}=0 \Rightarrow \frac{K_{t}}{K_{t \max }}=b_{t}$, we will get the equation for evaluation: 


$$
\widetilde{a}_{t}=-\ln \left(1-b_{t}\right)
$$

i.e.

$$
\widetilde{a}_{t}=F_{t}\left(b_{t}\right)
$$

Analyzing (4), we can conclude that the quality factor $\bar{A}_{t}(C)$ can be represented by two factors:

$$
\bar{A}_{t}(C)=\left\{\bar{B}_{t}(C), F_{t}(C)\right\}
$$

which correspond:

$$
\begin{gathered}
B_{t}(C) \Rightarrow b_{t}=\frac{K_{t}}{K_{t \max }}, \\
F_{t}(C) \Rightarrow R \subset A_{t} \times B_{t} \Rightarrow \widetilde{a}_{t}=F_{t}\left(b_{t}\right) \\
\text { when } \widetilde{a}_{t} \in A_{t} \quad b_{t} \in B_{t},
\end{gathered}
$$

that is $B_{t}$ is a factor, characterizing compliance degree of valid values of quality services indicator $\left(K_{t}\right)$ to maximum values $\left(K_{t \max }\right)$ - the quality factor representing the consumer's interest;

$F_{t}$ is a factor characterizing level of organization, "culture" of production, or factor of organizational and technical excellence of production process, based on represented costs of production's improvement which converts to reaching the indicator $K_{t}$.

The factor $F_{t}$ is a binary relation of factors $\bar{A}_{t}$ and $\bar{B}_{t}$ [3], $\quad$ i.e. $R \subset \bar{A}_{t} \times \bar{B}_{t}$ Type of function (4) determines the general tendency of the intersectionality of factors $\bar{A}_{t}$ and $\bar{B}_{t}$, and thereby characterizing that $\bar{A}_{t}$ includes a factor of the company's options to provide for achievement necessary value of $K_{t \max }$ [18-20].

We have shown it, with the help of the equation, describing the law of progressive development of quality service indicator, and his graphic representation (Figure 1). Considering the discreteness of the argument, we can formulate:

$$
b_{t}=1-\exp \left\{-\frac{a_{t}}{\eta}\right\}
$$

where $\eta$ is a constant factor.

Then, the limits to function's growth (6) may be practically limited by its established value, which can be reached when $\alpha=(3-4) \eta$. 
Assessment of impacts of factors of organizational and technical excellence of production on quality service is defined with movement of the rate of the indicator $b_{t}$ depending on $\eta_{t}$. Thus, geometrical sense of indicator $\eta_{t}$ is determined by length of subtangent at any point of the curve, as $\frac{d b_{t}}{d a_{t}}=\operatorname{tg} \varphi=\frac{1}{\eta}$. That shows the impact of the length of $\eta_{t}$ on steepness of the curve $b_{t}$.

Therefore, the rate of function's growing is the rate of the process. In so doing, with the growth of $\alpha_{t}$ that is multiple of $\eta_{t}$, the rate of growth is decreasing in $e$ times.

Out of here $\frac{d b_{t}}{d a_{t}}=\operatorname{tg} \varphi=\frac{1}{\eta}$ is a progression process intensity of $b_{t}$, characterizing the speed of quality service raising. With the changing $\eta_{t}$, the rate of raising process changes too. This particular finding, to some extent, corresponds to the technical and economic policy of intensification of technological processes in the production (creation) of technology in terms of limited resources (Figure 1.). Without minimizing the general influence of quality management principles on organizational capacity, particular attention should be drawn to the impact of the following principles: "systematic approach," "manager's leadership," and "personnel's involvement."

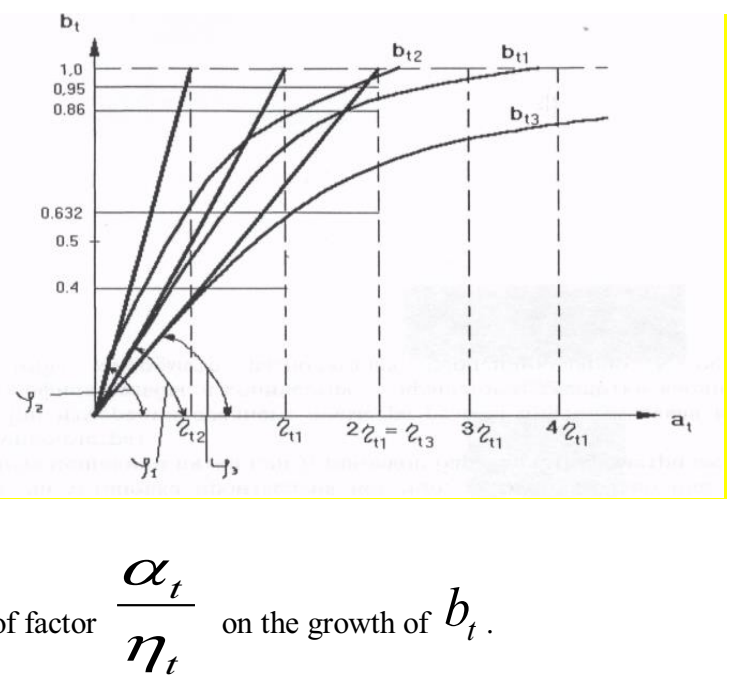

\section{Conclusions}

1. The impact of quality management principles "systematic approach," "manager's leadership," and "employee involvement" on test lab's organizational capacity contributes to the establishment of rational structure, development of a corporate culture of production, and adaptive process of operative management in decision making. 
2. The results of task solution in analyzing the impact of organizational factors on the quality of services provided proves the general possibility for a transformation of these questions from area of intuitive conceptions to a defined scientific field.

\section{References}

1. M. F. van Assen, Production Planning \& Control 32(2), 132-144 (2020) doi: 10.1080/09537287.2020.1716405

2. B. Danica, A. Rogosic, Total Quality Management \& Business Excellence 28(11-12), 1209-1226 (2017) doi: 10.1080/14783363.2015.1094369

3. L. S. LevinCompass, Consulting 5(1), 17-18 (2015) doi: 10.1080/10429247.1993.1141471

4. M. Haffar, W. Al-Karaghouli, R. Djebarni, G. Gbadamosi, Total Quality Management \& Business Excellence 30(11-12), 1367-1388 (2017) doi: 10.1080/14783363.2017.1369352

5. V. A. Bulakhov, Standards and Quality, 4 (2017)

6. K. M. Rakhlin. Standards and Quality, 1 (2011)

7. N. Vostrikova, All about Meat 5, 11-15 (2017)

8. G. P. S. Jadaun, Journal of Pharmaceutical Quality Assurance 3, 53-56 (2015)

9. A.V. Kartashova, Product quality control 1, 6-10 (2015)

10. Yu. Yu. Kortusova, Modern Scientific research and Innovation 3, 8 (2012)

11. Kamila Kowalik, Dorota Klimecka-Tatar, Production engineering archives 18, 31-34 (2017) doi: 10.30657/pea.2018.18.05

12. E. Bauer, Standards and Quality 12, 60-61 (2014)

13. ISO 9001:2015. Quality management systems — Requirements (IDT).

14. ISO 9000:2015. Quality management systems - Fundamentals and vocabulary (IDT)

15. W. Vetchagool, M. M. Augustyn, M. Tayles, Total Quality Management \& Business Excellence 32(3-4), 265-288 (2018) doi:10.1080/14783363.2018.1549938

16. J. García-Bernal, M. Ramírez-Alesón, Quality Management Journal 22(1-2), 23-37 (2015)

17. A. Jarvis, L. Morales, U. Ranadive, Achieving Customer Experience Excellence Through A Quality Management System (2016)

18. H. Guo, R. Zhang, Business and Management Horizons 2, 26-33 (2018)

19. A. Fundin, J. Lilja, Y. Lagrosen, B. Bergquist, Total Quality Management \& Business Excellence, dec (2020) doi:10.1080/14783363.2020.1863778

20. Y. Pambrenia, A. Khatibia, S. M. Ferdous, Azama and Jacquline Thama, Management Science Letters 9, 1397-1406 (2019) doi: 10.5267/j.msl.2019.5.011 